physics and the study of nuclear fusion as a possible source of industrial power. Most of the thermonuclear research now carried on at Harwell and Aldermaston will be moved to the new establishment. One of the immediate tasks at the new site, if approved, would be the construction of I.C.S.E. (Intermediate Current Stability Experiments), a large machine which (as announced at the Authority's annual press conference in July) will incorporate the results of experience with Zeta and of other studies in this field, both at home and abroad. It is planned that the total numbers employed at the proposed new establishment will rise to 1,000 and that this figure will be reached within four or five years.

\section{Divorce Statistics in Britain}

THE principal changes that have been introduced in the Civil Tables of the Registrar General's Statistical Review for 1957 which has been published recently relate to divorce statistics (The Registrar General's Statistical Review of England and Wales for the year 1957. Part 2: Tables, Civil. Pp. xii + 200. London: H.M. Stationery Office, 1959. 11s. $6 d$. net). Figures for divorces and annulments are now given by calendar year of marriage and age of spouses at marriage, so that the risk of divorce of different marriage cohorts may now be computed, and there are some other welcome new details on divorce. An appendix shows details of marriages by manner of solemnization in different countries. It is intended to publish this table at five-yearly intervals, and these data give a useful indication of the distribution of different religious groups in the country. It is of some interest that the proportion of civil marriages shows a fall, compared with 1952, for the first time since such marriages were instituted in 1836. In addition to these new figures, more detailed fertility tabulations giving better exposed-to-risk are also included in this volume.

\section{Sex Research}

The Division of Medical Sciences of the National Academy of Sciences--National Research Council is accepting applications for grants-in-aid of research for consideration by the Committee for Research in Problems of Sex. The funds for support of this programme are provided by the Rockefeller Foundation and the Ford Foundation. The Committee is concerned primarily with encouraging research on the mechanisms underlying sexual behaviour, with special emphasis on the higher mammals and man. Proposals involving endocrinological, neurological, psychological, anthropological, phylogenetic and genetic studies directed toward this objective are therefore invited. Requests that deal with the physiology of reproduction or with related biological and biochemical fields should be addressed to the Committee only if they give promise of shedding light upon behavioural mechanisms. Preliminary inquiries should be addressed to Room 411, Division of Medical Sciences, National Academy of SciencesNational Research Council, 2101 Constitution Avenue, N.W., Washington 25, D.C. Completed applications for the fiscal year 1960-61 should be postmarked on or before January 15, 1960.

\section{Variation in Lizards of the Leiocephalus cubensis Complex in Cuba and the Isla de Pinos}

Leiocephalus cubensis Gray has been regarded as one of the four species of this genus in Cuba and the Isla de Pinos, and has been known to occur throughout both islands in suitable habitats. Albert Schwartz has collected 388 specimens and studied additional material from various museums; this has resulted in the partition of $L$. cubensis into two species, each with four subspecies. $L$. cubensis is now known from Cuba and the Isla de Pinos, the Doce Leguas keys, and the Archipiélago de los Canarreos, where the new species, L. stictigaster, occurs in western Cuba and the Isla de Pinos. The status of Oriente lizards of this complex remains uncertain. Schwartz believes that stictigaster and cubensis arose from a common stock through isolation on western and central island masses during the Oligocene and Lower Miocene Periods. With the re-establishment of the island to approximately its present outline between the Lower and Middle Miocene, these two species extended their ranges gradually from the regions of differentiation. From modern distribution it appears that the gap between western stictigaster and eastern cubensis may not yet be closed. L. cubensis also has spread to the east into Oriente as well as the west into Matanzas and Habana (Bulletin of the Florida State Museum, Biological Sciences, 4, No. 4; 1959).

\section{Transparent Sintered Alumina-'Lucalox'}

SrNTERed or vitrified ceramic materials of polyphase composition are normally opaque owing to scattering of light by the different refractive indices of the component phases. Single-phase sintered ceramics are usually both opaque and porous owing to the difficulty of sintering refractory substances sufficiently well to produce optical contact between the grains. The General Electric Co. of America announces the experimental production of a material, under the trade name 'Lucalox', which is formed by pressing from alumina powder of small grain size and fired under conditions, presumably in vacuo and at a very high temperature, which permit almost com. plete sintering to occur. The product is non-porous and sufficiently transparent for print to be read through a thickness of the material in contact with the paper. Objects viewed at greater distances are, however, blurred as though through frosted glass. It retains the refractory qualities of alumina, and is said to be stable up to about $1.900^{\circ} \mathrm{C}$. Possible fields of use include envelopes for high-intensity light or radiant heat sources, as a superior alternative to fused silica. Light-transmission in the visible spectrum, through an unstated thickness, is said to be 90 per cent. Since the material is in effect a polycrystalline sapphire, it may offer an alternative to synthetic mono-crystalline sapphire for instrument bearings. Its electrical properties are not stated, but would presumably resemble those of sapphire; a permittivity of about 9.5 , loss angle between $10^{-4}$ and $10^{-3}$ at room temperature, and appreciable conductivity appearing around $300-500^{\circ} \mathrm{C}$., depending upon purity. The problem of production as a commercially satisfactory operation is said to be still under investigation.

\section{International Conference on Non-Destructive Test- ing}

THE third International Conference on NonDestructive Testing will be held in Tokyo during March 15-21. The Conference is intended to provide an opportunity for the exchange of information on 